\title{
Sex-Specific Moderation Effect of Age on the Associations Between Insomnia Symptoms and Various Psychological Distresses
}

This article was published in the following Dove Press journal: Nature and Science of Sleep

\author{
Hsi-Chung Chen (iD) ${ }^{1,2}$ \\ Chia-Yi Wu iD ${ }^{3-5}$ \\ Ming-Been Lee (iD) ${ }^{1,5-7}$ \\ Shih-Cheng Liao id 1,5,6 \\ Chia-Ta Chan ${ }^{5,7}$ \\ Chun-Ying Chen ${ }^{5}$ \\ 'Department of Psychiatry, National \\ Taiwan University Hospital, Taipei, \\ Taiwan; ${ }^{2}$ Center of Sleep Disorders, \\ National Taiwan University Hospital, \\ Taipei, Taiwan; ${ }^{3}$ School of Nursing, \\ National Taiwan University College of \\ Medicine, Taipei, Taiwan; ${ }^{4}$ Department of \\ Nursing, National Taiwan University \\ Hospital, Taipei, Taiwan; ${ }^{5}$ Taiwan Suicide \\ Prevention Center, Taipei, Taiwan; \\ ${ }^{6}$ Department of Psychiatry, National \\ Taiwan University College of Medicine, \\ Taipei, Taiwan; ${ }^{7}$ Department of \\ Psychiatry, Shin Kong Wu Ho-Su \\ Memorial Hospital, Taipei, Taiwan
}

Background: Insomnia is closely related to psychological distress. This study aims to examine the role of age and sex in the association between various psychological distresses and insomnia symptoms.

Participants and Methods: This population-based study used data provided by cumulative respondents of the annual survey of the Taiwan Suicide Prevention Center between 2006 and 2019. Potential respondents were aged $\geq 15$ years and were selected by a stratified proportional randomization method according to the distribution of population size, sex, and age in different geographic areas of Taiwan. The Five-Item Brief Symptom Rating Scale was used to measure insomnia symptoms and four psychological distresses: depression, anxiety, hostility, and inferiority. The independent relationship between insomnia symptoms with depression, anxiety, hostility, and inferiority was further examined according to age and sex. Results: A total of 28,649 participants were included (women, 50.2\%). The four types of psychological distress correlated differentially with insomnia symptoms. Concerning interaction effects, sex moderated the interaction effects between age with depression, anxiety, and hostility. In men, and not in women, age moderated the relationship between insomnia symptoms and all four psychological distresses. Specifically, the effect sizes of the associations between insomnia symptoms and depression, anxiety, and hostility showed an agedependent decreasing trend in men.

Conclusion: The associations between psychological distresses and insomnia symptoms varied in strength and according to age in a sex-specific manner.

Keywords: insomnia symptoms, moderation effect, psychological distress, sex-specific

\section{Introduction}

Emotional regulation is a key function of sleep, ${ }^{1}$ and the literature suggests that sleep-wake regulation and emotional control may share common neurobiological underpinnings. $^{2,3}$ Because insomnia features differential strengths of association with various physical ${ }^{4}$ and psychiatric disorders, ${ }^{5,6}$ insomnia is also considered to have different, but close, patterns of associations with various forms of psychological distress as well. ${ }^{7-9}$

The nature of stressors and stress responses from which psychological distress originates differs according to sex and evolve across age; ${ }^{10}$ hence, the association between insomnia and psychological distresses might also differ with sex and age. Concerning age, insomnia features the strongest association with depressive symptoms during adolescence. ${ }^{11}$ By contrast, depressive symptoms in older adults are
Correspondence: Chia-Yi Wu

School of Nursing, National Taiwan Jen-AI Road, Taipei 100, Taiwan Tel +886-2-23I23456 ext. 88430 Email jennycyw@ntu.edu.tw

Ming-Been Lee

Department of Psychiatry, National Taiwan

University Hospital, No. 7, Chung-Shan

S. Road, Taipei 100, Taiwan

Tel +886-2-23I 23456 Ext. 66784

Email mingbeen@ntu.edu.tw
Nature and Science of Sleep 2021:13 93-102 
more closely associated with daytime sleepiness than insomnia. $^{12,13}$ The abundant epidemiological research on insomnia has focused more on the effect of age on insomnia rather than on how factors correlated with insomnia change with age. The promise of the latter avenue of research is demonstrated by the finding that age moderates the relationship between insomnia and quality of life, hypnotics use, and marital status. ${ }^{14}$ However, whether the associations between insomnia and various forms of psychological distresses present to similar degrees in both younger and older adults remains unclear.

Various aspects of insomnia also reportedly differ according to sex: eg, prevalence rates, ${ }^{15}$ age of onset, ${ }^{16}$ psychosocial correlates, ${ }^{17,18}$ symptoms, ${ }^{19}$ pathophysiology, ${ }^{20}$ and psychiatric comorbidities. ${ }^{21}$ Further, women with major depressive disorders have a higher risk of developing sleep disturbances, $^{22}$ including hypersomnia, ${ }^{23}$ than do men. Similar findings were observed in adolescence: girls with emotional disturbances were at higher risk of developing sleep problems than were boys in the follow-up study. ${ }^{24}$ By contrast, the depressive symptoms of boys were more likely to co-occur with insomnia than were those of girls. ${ }^{25}$

Understanding how the association between forms of psychological distress and insomnia change according to age and sex is important to tailoring specific treatment strategies. ${ }^{26}$ Hence, sampling randomly from a nationally representative dataset of the Taiwanese population, the present study sought to (1) investigate the associations between various forms of psychological distress and insomnia symptoms using the Five-Item Brief Symptom Rating Scale (BSRS-5), (2) assess the effects of age on the associations identified in (1), and (3) evaluate the extent to which the effects identified in (2) differed according to sex.

\section{Participants and Methods Participants}

The present population-based study used the data provided by cumulative respondents to the annual survey performed by the Taiwan Suicide Prevention Center from 2006 to 2019; a computer-assisted telephone interview system is used to select potential participants from a database of landline telephone numbers, which was sampled with a stratified proportional randomization method based on the distribution of population size, age, and sex in different geographic areas of Taiwan. ${ }^{27}$ Approximately 2100 participants were recruited each year for analysis (with a sampling error of $+2.10 \%$ in $95 \%$ confidence interval). All participants were aged $\geq 15$ years old and agreed to participate in the survey anonymously. All data were collected by well-trained interviewers over the telephone. The representation of the sample is ensured by the chi-square goodness-of-fit test and the raking weighting method. In addition to collecting the participants' results on the BSRS-5, we obtained basic demographic data, including age, sex, level of education, marital status, and occupation.

\section{Ethical Approval}

The authors assert that all procedures contributing to this work comply with the ethical standards of the relevant national and institutional committees on human experimentation and with the Helsinki Declaration of 1975, as revised in 2008. All participants provided oral consent prior to survey commencement by telephone interview. This study was approved by the Institutional Review Board of the National Taiwan University Hospital (N0. 201204034RIC).

\section{Assessment of Psychological Distress Using the BSRS-5}

This study used the BSRS-5 to measure four dimensions of common psychological distresses and insomnia. The BSRS-5 is a five-item self-report questionnaire with a total score cut-off of six or more (sensitivity: $78.0 \%$; specificity: $74.3 \%$ ) for the identification of psychiatric morbidity and the global severity of clinical symptoms. ${ }^{28,29}$ Brief instruction was provided to the participants before the administration of BSRS- 5 to ensure its validity. Participants were asked to rate the degree to which they felt distressed from each dimension of BSRS5 during the week preceding the assessment. The BSRS-5 contains the following five items: (1) feeling tense or keyed up; (2) feeling blue; (3) feeling easily annoyed or irritated; 4) feeling inferior to others; and 5) having trouble falling asleep, for example, initial, maintenance, and late insomnia. A 5-point Likert system was used to rate each item of the BSRS- 5 as follows: 0 , not at all; 1 , a little bit; 2, moderately; 3 , quite a bit; 4 , extremely. A total score was calculated for each respondent. The five items of the BSRS-5 represent the psychopathology of anxiety, depression, hostility, inferiority, and insomnia, respectively. The insomnia item of the BSRS-5 was used as the dependent variable for the following statistical analyses. 


\section{Statistical Analyses}

Statistical Analysis System (version 9.1, SAS Institute) was used for all analyses. In addition to performing descriptive statistics, independent Student's $t$-tests or ANOVA tests were used to compare the severity of insomnia symptoms according to sociodemographic and clinical variables for univariate analyses. A Spearman's rank correlation analysis was used to evaluate the linear relationship between insomnia symptoms and the other four items in the BSRS-5. For the multivariable analyses, multiple ordinal logistic regression analyses were used to assess the independent associations between the four dimensions of psychological distresses with the severity of insomnia symptoms. In addition to the survey year, all sociodemographic factors that differed significantly according to the severity of insomnia symptoms were specified into the ordinal logistic regression models to control for the confounding effects. To prevent collinearity between the four dimensions of the psychological distresses, each form of psychological distress was specified into separate ordinal logistic regression models as the independent variable. To examine the moderation effect of age, the statistical significance for the interaction terms of each psychological distress with age was tested. Three-way interaction terms for sex, age, and each psychological distress were also evaluated to examine if there is a sex difference in the interaction effects between age and each psychological distress. Analyses were then stratified by sex to illustrate sex-based differences in the moderation effect of age. The statistical significance level was set to $p<0.05$.

\section{Results}

A total of 28,649 individuals (women, 50.2\%) participated in the surveys. Table 1 summarizes the relationship between sociodemographic characteristics and clinical variables according to the severity of insomnia symptoms. Participants who were older, women, less educated, divorced/widowed, or unemployed were associated with more severe insomnia symptoms. Those whose total BSRS-5 scores exceeded 5 had more severe insomnia symptoms (Table 1).

Table 2 illustrates the between-item associations of the BSRS-5; all the associations were statistically significant, with Spearman's rank correlation coefficients ranging from 0.21 to 0.50 . Specifically, the correlation coefficients of insomnia symptoms with the other four items of the BSRS-5 ranged from 0.21 to 0.32 . Depression had the
Table I Characteristics of Participants $(n=28,649)$

\begin{tabular}{|c|c|c|c|}
\hline & Total & $\begin{array}{l}\text { Severity of } \\
\text { Insomnia } \\
\text { Symptoms }\end{array}$ & \multirow[t]{2}{*}{$\begin{array}{l}p \text { for } \\
\text { t-test/ } \\
\text { ANOVA }\end{array}$} \\
\hline & n (\%) & Mean \pm SD & \\
\hline \multicolumn{4}{|l|}{ Age (years) } \\
\hline$<25$ & $4570(16.0)$ & $0.25 \pm 0.65$ & $<0.001$ \\
\hline $25-34$ & $5354(18.7)$ & $0.38 \pm 0.78$ & \\
\hline $35-44$ & $5445(19.0)$ & $0.40 \pm 0.81$ & \\
\hline $45-54$ & $5282(18.5)$ & $0.45 \pm 0.85$ & \\
\hline $55-64$ & $4018(14.0)$ & $0.49 \pm 0.89$ & \\
\hline$\geq 65$ & $3949(13.8)$ & $0.49 \pm 0.90$ & \\
\hline \multicolumn{4}{|l|}{ Sex } \\
\hline Men & 14,260 (49.8) & $0.36 \pm 0.79$ & $<0.001$ \\
\hline Women & $14,389(50.2)$ & $0.45 \pm 0.84$ & \\
\hline \multicolumn{4}{|l|}{ Education } \\
\hline College and above & $9606(33.5)$ & $0.33 \pm 0.72$ & $<0.001$ \\
\hline $\begin{array}{l}\text { Senior high school and } \\
\text { below }\end{array}$ & $18,970(66.2)$ & $0.45 \pm 0.86$ & \\
\hline \multicolumn{4}{|l|}{ Marital status } \\
\hline Single & $9009(34.0)$ & $0.35 \pm 0.76$ & $<0.001$ \\
\hline Married & $16,444(62.0)$ & $0.42 \pm 0.81$ & \\
\hline Divorced/widowed & $953(3.6)$ & $0.75 \pm 1.13$ & \\
\hline \multicolumn{4}{|l|}{ Job status } \\
\hline With current job & $16,213(56.6)$ & $0.39 \pm 0.79$ & $<0.001$ \\
\hline Without current job & $12,388(43.2)$ & $0.44 \pm 0.85$ & \\
\hline \multicolumn{4}{|l|}{$\begin{array}{l}\text { Brief Symptom Rating } \\
\text { Scale }\end{array}$} \\
\hline$\geq 6$ & $214 \mid(7.5)$ & $1.87 \pm 1.33$ & $<0.001$ \\
\hline$<5$ & $26,508(92.5)$ & $0.29 \pm 0.62$ & \\
\hline
\end{tabular}

strongest correlation with insomnia symptoms, and inferiority the weakest.

Table 3 summarizes the independent associations between the various forms of psychological distress with insomnia symptoms. All four common psychological distresses remained correlated with insomnia symptoms after controlling for covariates. Depression was most to accompany insomnia symptoms in aggravating a respondent (odds ratio (OR): 3.01, 95\% confidence interval (CI): 2.90-3.13). While inferiority also correlated with insomnia symptoms, its effect size was the smallest of the four forms of psychological distress (OR: 2.21, 95\% CI: 2.13-2.30). Specifically, the point estimate and $95 \%$ CI of inferiority did not overlap with any of the other three psychological distresses. The details of the full models were summarized in Supplementary Table S1. Once stratified according to age, the severity of four forms of psychological distress remains significantly correlated 
Table 2 Spearman's Rank Correlation Analyses for the Items of BSRS-5

\begin{tabular}{|c|c|c|c|c|c|c|c|}
\hline & $\mathbf{I}$ & 2 & 3 & 4 & 5 & 6 & 7 \\
\hline I. Trouble falling asleep & 1 & & & & & & \\
\hline 2. Feeling tense or keyed up & $0.30 *$ & I & & & & & \\
\hline 3. Feeling easily annoyed or irritated & $0.29 *$ & $0.43^{*}$ & 1 & & & & \\
\hline 4. Feeling blue & $0.32 *$ & $0.46^{*}$ & $0.50 *$ & I & & & \\
\hline 5. Feeling inferior to others & $0.21^{*}$ & $0.37^{*}$ & $0.36 *$ & $0.39 *$ & I & & \\
\hline 6. Total scores of BSRS- 5 & $0.65^{*}$ & $0.6 I^{*}$ & $0.69 *$ & $0.67 *$ & $0.57^{*}$ & I & \\
\hline 7. Total scores of BSRS-5 except for the sleep item & $0.35^{*}$ & $0.66^{*}$ & $0.76^{*}$ & $0.72 *$ & $0.64 *$ & $0.91 *$ & 1 \\
\hline
\end{tabular}

Note: $* p<0.01$.

Abbreviation: BSRS-5, the Five-Item Brief Symptom Rating Scale.

Table 3 The Ordinal Logistic Regression Analyses Examining the Individual Relationship Between Various Psychological Distresses with Insomnia Symptoms, Stratified by Age*

\begin{tabular}{|c|c|c|c|c|c|c|c|c|}
\hline \multirow{4}{*}{$\begin{array}{l}\text { Psychological } \\
\text { Distresses }\end{array}$} & \multicolumn{7}{|c|}{ Insomnia Symptoms } & \multirow{4}{*}{$\begin{array}{l}\text { p-value for Age } \\
\text { Interaction }\end{array}$} \\
\hline & \multirow[t]{2}{*}{ Total } & \multicolumn{6}{|l|}{ Age } & \\
\hline & & $<25$ & $25-34$ & $35-44$ & $45-54$ & $55-64$ & $\geq 65$ & \\
\hline & OR $(95 \% \mathrm{Cl})$ & OR $(95 \% \mathrm{Cl})$ & OR (95\% Cl) & OR $(95 \% \mathrm{Cl})$ & OR $(95 \% \mathrm{Cl})$ & OR $(95 \% \mathrm{Cl})$ & OR $(95 \% \mathrm{Cl})$ & \\
\hline Anxiety & $2.89(2.78-3.00)$ & $3.14(2.83-3.48)$ & $3.38(3.09-3.69)$ & $2.84(2.60-3.10)$ & $2.90(2.66-3.17)$ & $2.74(2.47-3.04)$ & $2.21(1.98-2.47)$ & $<0.001$ \\
\hline Hostility & $2.70(2.60-2.79)$ & $3.11(2.82-3.43)$ & $2.62(2.42-2.82)$ & $2.56(2.37-2.76)$ & $2.78(2.57-3.02)$ & $2.68(2.42-2.97)$ & $2.55(2.30-2.84)$ & 0.06 \\
\hline Depression & $3.01(2.90-3.13)$ & $3.14(2.83-3.48)$ & $3.06(2.81-3.33)$ & $2.96(2.73-3.22)$ & $3.33(3.05-3.64)$ & $2.87(2.60-3.17)$ & $2.63(2.35-2.93)$ & 0.08 \\
\hline Inferiority & $2.21(2.13-2.30)$ & $2.32(2.11-2.55)$ & $2.39(2.20-2.59)$ & $2.05(1.89-2.23)$ & $2.35(2.16-2.56)$ & $1.87(1.70-2.06)$ & $2.31(2.06-2.59)$ & $<0.001$ \\
\hline
\end{tabular}

Note: *All models adjusted for sex, age, education, marital status, job status, and survey year.

with that of insomnia symptoms across all age spans. However, the strength of these associations varied with age (Figure 1A). Thus, the interaction between each type of psychological distress with age was examined, revealing that age moderates the relationship between anxiety ( $p$ for the interaction term $<0.001$ ) and inferiority ( $p$ for the interaction term $<0.001$ ) with insomnia symptoms.

To examine whether there are sex differences in terms of the interaction effects between age and each psychological distress, the three-way interaction terms (sex X, age X, each psychological distress) were tested. The results showed that, except for "feeling inferiority to others" $(p=0.22)$, the threeway interaction terms are significant for "feeling tense or keyed up" ( $p<0.001)$, "feeling easily annoyed or irritated" $(p<0.001)$, and "feeling blue" $(p<0.001)$. When further stratified by sex, the overall association patterns remained: depression had the greatest effect size, and inferiority the smallest (Tables 4 and 5). The details of the full models for both sexes were summarized in Supplementary Tables S2 and S3. In terms of the moderation effect of age, all of the associations between the four dimensions of psychological distresses with insomnia were significantly moderated by age among men (Table 4). The strength of the associations between the three psychological distresses other than inferiority with insomnia illustrates an age-dependent decreasing trend (Figure 1B). In terms of inferiority, the strength of associations followed an age-related pattern, in which the age group of 35-44 years (OR: 1.80, 95\% CI: 1.61-2.02) and 55-64 years (OR: 1.67, 95\% CI: $1.45-1.91$ ) have the smallest effect size. The effect sizes and their $95 \%$ CI between inferiority with the other three psychological distresses did overlap after the age of 65 . By contrast, no moderation effects of age were detected among women (Table 5). The relative effect sizes across life span were similar for the four psychological distresses among women (Figure 1C).

\section{Discussion}

By sampling from the cumulative respondents to a national survey, the present study examined the patterns of association between common forms of psychological distress with insomnia symptoms and how they differed with age and sex. Our findings indicate that various psychological distresses correlate with insomnia symptoms; the effect sizes of these associations differ in magnitude and are moderated differentially by age among men. To the best of our knowledge, the present study is the first to report the moderation effect of age and its dependence on sex. 


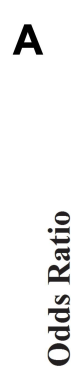

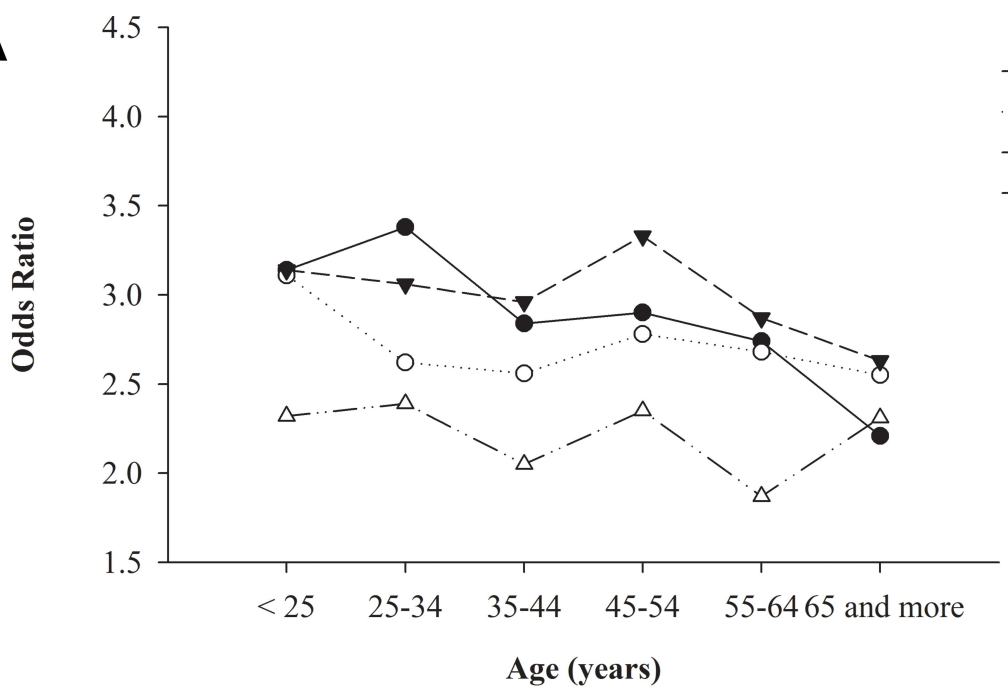

B

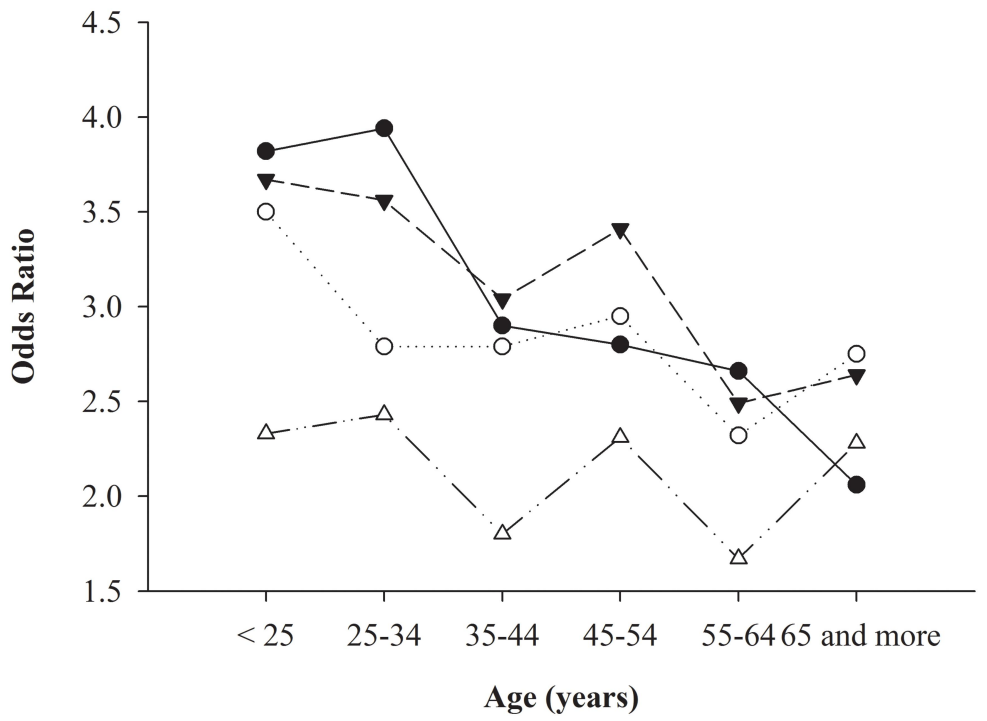

C

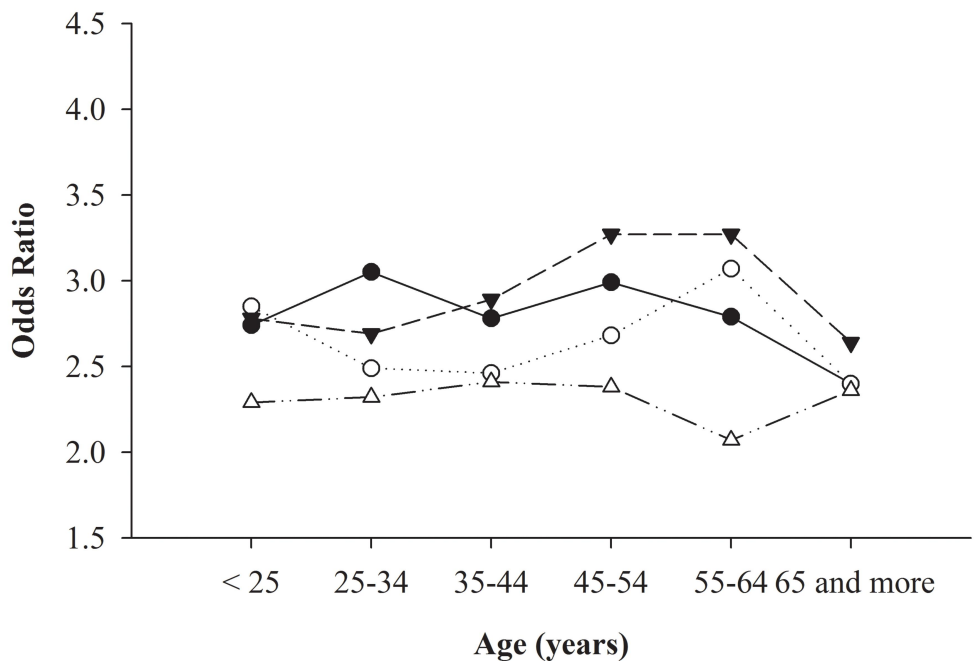

Figure I The age trends of the associations between various psychological distresses and insomnia symptoms. Panel (A) total participants, (B) men, (C) women. 
Table 4 The Ordinal Logistic Regression Analyses Examining the Individual Relationship Between Various Psychological Distresses with Insomnia Symptoms in Men, Stratified by Age*

\begin{tabular}{|c|c|c|c|c|c|c|c|c|}
\hline \multirow{4}{*}{$\begin{array}{l}\text { Psychological } \\
\text { Distresses }\end{array}$} & \multicolumn{7}{|c|}{ Insomnia Symptoms } & \multirow{4}{*}{$\begin{array}{l}\text { p-value for Age } \\
\text { Interaction }\end{array}$} \\
\hline & \multirow[t]{2}{*}{ Total } & \multicolumn{6}{|l|}{ Age } & \\
\hline & & $<25$ & $25-34$ & $35-44$ & $45-54$ & $55-64$ & $\geq 65$ & \\
\hline & OR $(95 \% \mathrm{Cl})$ & OR $(95 \% \mathrm{Cl})$ & OR (95\% Cl) & OR $(95 \% \mathrm{Cl})$ & OR $(95 \% \mathrm{Cl})$ & OR $(95 \% \mathrm{Cl})$ & OR $(95 \% \mathrm{Cl})$ & \\
\hline Anxiety & $2.98(2.82-3.16)$ & $3.82(3.25-4.50)$ & $3.94(3.44-4.50)$ & $2.90(2.55-3.31)$ & $2.80(2.47-3.18)$ & $2.66(2.29-3.10)$ & $2.06(1.75-2.42)$ & $<0.001$ \\
\hline Hostility & $2.81(2.67-2.96)$ & $3.50(3.01-4.07)$ & $2.79(2.48-3.13)$ & $2.79(2.48-3.13)$ & $2.95(2.61-3.33)$ & $2.32(2.02-2.67)$ & $2.75(2.36-3.20)$ & 0.03 \\
\hline Depression & $3.13(2.96-3.30)$ & $3.67(3.14-4.30)$ & $3.56(3.14-4.04)$ & $3.04(2.69-3.42)$ & 3.41 (2.99-3.89) & $2.49(2.16-2.86)$ & $2.64(2.26-3.08)$ & $<0.001$ \\
\hline Inferiority & $2.12(2.01-2.23)$ & $2.33(2.02-2.69)$ & $2.43(2.16-2.73)$ & $1.80(1.61-2.02)$ & $2.31(2.06-2.60)$ & $1.67(1.45-1.91)$ & $2.28(1.95-2.67)$ & $<0.001$ \\
\hline
\end{tabular}

Note: *All models adjusted for sex, age, education, marital status, job status and, survey year.

Table 5 The Ordinal Logistic Regression Analyses Examining the Individual Relationship Between Various Psychological Distresses with Insomnia Symptoms in Women, Stratified by Age*

\begin{tabular}{|c|c|c|c|c|c|c|c|c|}
\hline \multirow{4}{*}{$\begin{array}{l}\text { Psychological } \\
\text { Distresses }\end{array}$} & \multicolumn{7}{|c|}{ Insomnia Symptoms } & \multirow{4}{*}{$\begin{array}{l}\text { p-value for Age } \\
\text { Interaction }\end{array}$} \\
\hline & \multirow[t]{2}{*}{ Total } & \multicolumn{6}{|l|}{ Age } & \\
\hline & & $<25$ & $25-34$ & $35-44$ & $45-54$ & $55-64$ & $\geq 65$ & \\
\hline & OR $(95 \% \mathrm{Cl})$ & OR $(95 \% \mathrm{Cl})$ & OR (95\% Cl) & OR $(95 \% \mathrm{Cl})$ & OR $(95 \% \mathrm{Cl})$ & OR $(95 \% \mathrm{Cl})$ & OR $(95 \% \mathrm{Cl})$ & \\
\hline Anxiety & $2.81(2.67-2.97)$ & $2.74(2.39-3.13)$ & $3.05(2.71-3.44)$ & $2.78(2.47-3.14)$ & $2.99(2.64-3.38)$ & $2.79(2.42-3.22)$ & $2.40(2.06-2.80)$ & 0.47 \\
\hline Hostility & $2.62(2.49-2.75)$ & $2.85(2.50-3.25)$ & $2.49(2.25-2.75)$ & $2.46(2.22-2.72)$ & $2.68(2.39-2.99)$ & $3.07(2.65-3.56)$ & $2.40(2.07-2.79)$ & 0.07 \\
\hline Depression & $2.92(2.77-3.07)$ & $2.78(2.41-3.19)$ & $2.69(2.39-3.03)$ & $2.89(2.57-3.24)$ & $3.27(2.90-3.70)$ & $3.27(2.84-3.77)$ & $2.64(2.25-3.09)$ & 0.42 \\
\hline Inferiority & $2.31(2.19-2.44)$ & $2.29(2.02-2.60)$ & $2.32(2.07-2.60)$ & $2.41(2.14-2.72)$ & $2.38(2.10-2.70)$ & $2.07(1.81-2.38)$ & $2.36(1.99-2.79)$ & 0.67 \\
\hline
\end{tabular}

Note: *All models adjusted for sex, age, education, marital status, job status and, survey year.

\section{Different Strengths of Associations Between Various Psychological Distresses and Insomnia Symptoms}

The forms of psychological distress measured by the BSRS-5 have also been included in several psychometric scales for measuring depression symptomology. ${ }^{30-32}$ Depression, anxiety, and hostility are categorized as affective symptoms; inferiority as a cognitive symptom; and insomnia as a somatic symptom. A recent network analysis revealed different associations between the items of the inventory of depressive symptomatology. Specifically, depression was partially associated with insomnia, but irritability (a symptom of hostility), anxiety, and interpersonal hypersensitivity (a symptom of inferiority) were not directly associated with insomnia. ${ }^{33}$ Our findings also agreed with the previous observation of different coworsening patterns between insomnia symptoms and the four psychological distresses. Specifically, when compared with the cognitive symptom of inferiority, affective symptoms (depression, anxiety, and hostility) measured by the BSRS-5 were more likely to worsen in tandem with insomnia symptoms. The greater effect size between affective symptoms and insomnia may be attributable to the subcortical areas that underlie both emotion control and sleep-wake regulation. ${ }^{1}$ Furthermore, affective symptoms are often the final common pathway for various psychopathologies that might trigger insomnia. An indirect association between insomnia symptoms and the cognitive symptom of inferiority mediated by affective symptoms would account for the smaller effect size of their association.

\section{Sex-Specific Moderation Effect of Age}

Previous research has indicated that the strengths of the associations between common mental disorders and insomnia do not vary with age. ${ }^{14}$ When analyzing the participants as one group, we found that age only moderated the relationships between insomnia symptoms and anxiety or inferiority. When we stratified the analysis according to sex, age was found to moderate all four forms of psychological distresses among men. By contrast, the association between any form of psychological distress 
and insomnia symptoms retained a similar degree of strength across life among women.

Age-dependent decline of effect sizes among men was found in the relationships between depression, anxiety, and hostility with insomnia symptoms. These findings may be ascribed to the well-documented age-dependent increase in the prevalence of insomnia; ${ }^{34,35} \mathrm{eg}$, relative to young adults, older adults with depression report more somatic symptoms and less affective-cognitive symptoms. ${ }^{36-38}$ By contrast, the weakest association between the severity of inferiority and insomnia symptoms was found among middle-aged men. As mid-life crises experienced by men may encompass inferiority, middle-aged men may adapt with greater ease to changes in inferiority as a normal developmental task and not necessarily suffer from sleep-wake disturbances as a result. However, no moderation effect of age was identified in women. This finding may be ascribed to sex-based differences in sleep physiology, life experiences, and social expectations. ${ }^{39}$

\section{Sex-Based Differences in the Moderation Effect of Age}

In sleep physiology, sleep structure changes with normal aging: total sleep duration, rapid eye movement, slowwave sleep, and sleep efficiency decrease, while arousal rates increase. ${ }^{40}$ The normal aging process increases the risk of insomnia that may not accompany an increased risk of psychological distress. Compared with older men, older women experience greater decreases in total sleep duration and sleep efficiency across age. ${ }^{41}$ This difference may expose older women to a heightened risk of developing psychological distress, which shares a pathological mechanism with the deterioration of sleep function. ${ }^{42}$ Eventually, the sex difference in the aging process of sleep physiology leads to comparable strength of association between psychological distresses and insomnia symptoms in the late life of women.

The previous study also found that women are more likely to be predisposed to psychological distresses and insomnia across all age groups, ${ }^{43-45}$ report mental distress and somatic symptoms, ${ }^{23}$ and rank psychological distresses as the main cause of insomnia. ${ }^{18}$ By contrast, men are more likely to express emotional distress by nonaffective manners with age due to social expectations and an increased self-inhibition in emotional expression. ${ }^{46,47}$ Meanwhile, men are also more likely to rank job stress, as the main cause of insomnia. ${ }^{18}$ These sex-based differences may also contribute to the comparable associations between the severity of psychological distress with insomnia symptoms in younger and older women.

\section{Implications}

Our findings have several implications. First, the differential effect sizes between various psychological distresses and insomnia symptoms suggest that affective symptoms, compared with cognitive symptoms, may induce different levels of hyperarousal. Furthermore, the moderation effect of age suggests that the impact of psychological distresses on the arousal system (arousability) may vary with age, particularly in males. Because emotional and cognitive hyperarousal has been defined as one of the core components in the modern pathomechanism models of insomnia, ${ }^{52,53}$ our findings of age- and sex-specific effects help to refine the current theoretical schema. Second, a shared biological vulnerability has been suggested in individuals who had co-occurring mood disorders and insomnia and those who had insomnia only; ${ }^{54}$ our findings echo the elevated risk of mood disturbances in individuals with insomnia symptoms. Besides, the age- and sex-specific effect further implicates that young males who have insomnia symptoms might be exposed to a higher risk of concurrence or of developing psychological distresses. This finding suggests the significance of public health to investigate and intervene in insomnia symptoms in young males.

\section{Limitations}

This study is subject to several limitations. First, its crosssectional design precluded causal inferences and the distinction between age and cohort effects. Second, participants in this study joined the annual survey anonymously. Hence, we risked having sampled duplicated data. However, the number of eligible participants ranged between 18 and 20 million between 2006 and 2019. ${ }^{48}$ Hence, the risk of duplicated participants should be very low. Third, physical morbidities were not controlled for in this study. The association between psychological distresses with insomnia symptoms could be biased away from the null under the confounding effect of physical comorbidities. Because physical illness is more prevalent in older adults, while we expect the moderation effect of age to remain even if the confounding effects of physical morbidities are partialled out, it is unclear whether the sex-based differences would persist. Besides, even if the prevalence of physical morbidities increases with age, the association between physical morbidities and major depressive disorder is reportedly low among older adults. ${ }^{49}$ 
Hence, the possible confounding effects of physical morbidities in this study might be modest. Fourth, we did not control for the influence of hypnotics use, which is expected to compromise the strength of the association between psychological distresses and insomnia symptoms. Because hypnotics are used more frequently with age, ${ }^{50}$ the confounding effects of hypnotics use may inflate the moderation effect of age in both sexes. However, the robustness of the malespecific moderation effect of age in this study is assured by the lack of this finding among the women respondents despite the more frequent use of hypnotics among older women than men in Taiwan. ${ }^{51}$ Finally, in order to prevent statistical collinearity, this study only specified one type of psychological distress in each regression model. Hence, cooccurrences of psychological distresses may also confound our main findings, including the sex-specific moderation effect. However, the higher rates of co-occurring psychopathologies could not explain the higher rate of insomnia among women. ${ }^{17,18}$ This evidence mitigates the impact of confounding co-occurring psychopathologies on our main findings.

\section{Conclusions}

The strong association between insomnia symptoms and non-psychotic psychopathology renders insomnia symptoms an effective probe to detect various psychological distresses, especially in a culture that tends to somatize psychopathology. ${ }^{55}$ The data presented herein expands our knowledge of how age influences the associations between common psychological distresses and insomnia symptoms, help to gain insight into the underlying psychopathology that co-occurs with insomnia symptoms across life, and will help to inform the development of tailored interventions to address insomnia symptoms. Mechanisms that underlie age-mediated moderation of insomnia symptoms and its sex-based differences warrant further investigation.

\section{Abbreviations}

BSRS-5, the Five-Item Brief Symptom Rating Scale; CI, confidence interval; OR, odds ratio.

\section{Data Sharing Statement}

All data and materials related to the study can be obtained by contacting the corresponding author.

\section{Acknowledgments}

The authors thank our colleagues at the Taiwan Suicide Prevention Center for their help in statistical analysis. This work has been done at the Department of Psychiatry, National Taiwan University Hospital and Taiwan Suicide Prevention Center, Taipei, Taiwan.

\section{Author Contributions}

All authors made a significant contribution to the work reported, whether that is in the conception, study design, execution, acquisition of data, analysis and interpretation, or in all these areas; took part in drafting, revising or critically reviewing the article; gave final approval of the version to be published; have agreed on the journal to which the article has been submitted; and agree to be accountable for all aspects of the work.

\section{Funding}

The study was supported by the Ministry of Health and Welfare, Executive Yuan, Taiwan (grant number: M08B811). The sponsor has no role in any of the stages from study design to submission of the paper for publication.

\section{Disclosure}

The authors report no financial or non-financial conflicts of interest for this work.

\section{References}

1. Yoo SS, Gujar N, Hu P, Jolesz FA, Walker MP. The human emotional brain without sleep-a prefrontal amygdala disconnect. Curr Biol. 2007;17(20):R877-878. doi:10.1016/j.cub.2007.08.007

2. Saper CB, Cano G, Scammell TE. Homeostatic, circadian, and emotional regulation of sleep. J Comp Neurol. 2005;493(1):92-98. doi:10.1002/cne.20770

3. Gehrman PR, Meltzer LJ, Moore M, et al. Heritability of insomnia symptoms in youth and their relationship to depression and anxiety. Sleep. 2011;34(12):1641-1646. doi:10.5665/sleep.1424

4. Helbig AK, Stöckl D, Heier M, et al. Relationship between sleep disturbances and multimorbidity among community-dwelling men and women aged 65-93 years: results from the KORA age study. Sleep Med. 2017;33:151-159. doi:10.1016/j.sleep.2017.01.016

5. Taylor DJ, Lichstein KL, Durrence HH, Reidel BW, Bush AJ. Epidemiology of insomnia, depression, and anxiety. Sleep. 2005;28 (11):1457-1464. doi:10.1093/sleep/28.11.1457

6. Kim BS, Jeon HJ, Hong JP, et al. DSM-IV psychiatric comorbidity according to symptoms of insomnia: a nationwide sample of Korean adults. Soc Psychiatry Psychiatr Epidemiol. 2012;47(12):2019-2033. doi:10.1007/s00127-012-0502-0

7. Kaneita Y, Ohida T, Osaki Y, et al. Association between mental health status and sleep status among adolescents in Japan: a nationwide cross-sectional survey. J Clin Psychiatry. 2007;68(9):1426-1435. doi:10.4088/JCP.v68n0916

8. Sivertsen B, Salo P, Mykletun A, et al. The bidirectional association between depression and insomnia: the HUNT study. Psychosom Med. 2012;74(7):758-765. doi:10.1097/PSY.0b013e3182648619

9. Bao YP, Han Y, Ma J, et al. Cooccurrence and bidirectional prediction of sleep disturbances and depression in older adults: meta-analysis and systematic review. Neurosci Biobehav Rev. 2017;75:257-273. doi:10.1016/j.neubiorev.2017.01.032 
10. Kunzmann U, Rohr M, Wieck C, Kappes C, Wrosch C. Speaking about feelings: further evidence for multidirectional age differences in anger and sadness. Psychol Aging. 2017;32(1):93-103. doi:10.1037/pag0000142

11. Urrila AS, Karlsson L, Kiviruusu O, Pelkonen M, Strandholm T, Marttunen M. Sleep complaints among adolescent outpatients with major depressive disorder. Sleep Med. 2012;13(7):816-823. doi:10.1016/j.sleep.2012.04.012

12. Lai HC, Hsu NW, Chou P, Chen HC. The associations between various sleep-wake disturbances and depression in community-dwelling older adults- the Yilan study, Taiwan. Aging Ment Health. 2020;24(5):717-724. doi:10.1080/ 13607863.2019.1582006

13. Leblanc M-F, Desjardins S, Desgagné A. Sleep problems in anxious and depressive older adults. Psychol Res Behav Manag. 2015;8:161-169. doi:10.2147/PRBM.S80642

14. Stewart R, Besset A, Bebbington P, et al. Insomnia comorbidity and impact and hypnotic use by age group in a national survey population aged 16 to 74 years. Sleep. 2006;29(11):1391-1397. doi:10.1093/ sleep/29.11.1391

15. Silverstein B. Gender differences in the prevalence of somatic versus pure depression: a replication. Am $J$ Psychiatry. 2002;159 (6):1051-1052. doi:10.1176/appi.ajp.159.6.1051

16. Johnson EO, Roth T, Schultz L, Breslau N. Epidemiology of DSM-IV insomnia in adolescence: lifetime prevalence, chronicity, and an emergent gender difference. Pediatrics. 2006;117(2):e247e256. doi:10.1542/peds.2004-2629

17. Li RHY, Wing YK, Ho SC, Fong SYY. Gender differences in insomnia-a study in the Hong Kong Chinese population. $J$ Psychosom Res. 2002;53(1):601-609. doi:10.1016/S0022-3999(02)00437-3

18. Lindberg E, Janson C, Gislason T, Björnsson E, Hetta J, Boman G. Sleep disturbances in a young adult population: can gender differences be explained by differences in psychological status? Sleep 1997;20(6):381-387. doi:10.1093/sleep/20.6.381

19. Jaussent I, Dauvilliers Y, Ancelin ML, et al. Insomnia symptoms in older adults: associated factors and gender differences. Am J Geriatr Psychiatry. 2011;19(1):88-97. doi:10.1097/JGP.0b013e3181e049b6

20. Guidozzi F. Gender differences in sleep in older men and women. Climacteric. 2015;18(5):715-721. doi:10.3109/13697137.201 5.1042451

21. Hale L, Do DP, Basurto-Davila R, et al. Does mental health history explain gender disparities in insomnia symptoms among young adults? Sleep Med. 2009;10(10):1118-1123. doi:10.1016/j. sleep.2008.12.011

22. Kornstein SG, Schatzberg AF, Thase ME, et al. Gender differences in chronic major and double depression. J Affect Disord. 2000;60 (1):1-11. doi:10.1016/S0165-0327(99)00158-5

23. Barsky AJ, Peekna HM, Borus JF. Somatic symptom reporting in women and men. J Gen Intern Med. 2001;16(4):266-275. doi:10.1046/j.1525-1497.2001.016004266.x

24. Wang B, Isensee C, Becker A, et al. Developmental trajectories of sleep problems from childhood to adolescence both predict and are predicted by emotional and behavioral problems. Front Psychol. 2016;7:1874. doi:10.3389/fpsyg.2016.01874

25. Sivertsen B, Harvey AG, Lundervold AJ, Hysing M. Sleep problems and depression in adolescence: results from a large population-based study of Norwegian adolescents aged 16-18 years. Eur Child Adolesc Psychiatry. 2014;23(8):681-689. doi:10.1007/s00787-013-0502-y

26. Broström A, Wahlin $\AA$, Alehagen U, Ulander M, Johansson P. Sexspecific associations between self-reported sleep duration, depression, anxiety, fatigue and daytime sleepiness in an older community-dwelling population. Scand J Caring Sci. 2018;32 (1):290-298. doi:10.1111/scs.12461

27. Isaac V, Wu CY, McLachlan CS, Lee MB. Associations between health-related self-efficacy and suicidality. BMC Psychiatry. 2018;18(1):126. doi:10.1186/s12888-018-1705-z
28. Lee MB, Liao SC, Lee YJ, et al. Development and verification of validity and reliability of a short screening instrument to identify psychiatric morbidity. $J$ Formos Med Assoc. 2003;102 (10):687-694.

29. Chen HC, Wu CH, Lee YJ, Liao SC, Lee MB. Validity of the five-item brief symptom rating scale among subjects admitted for general health screening. $J$ Formos Med Assoc. 2005;104 (11):824-829.

30. Beck AT, Steer RA, Ball R, Ranieri W. Comparison of beck depression inventories -IA and -II in psychiatric outpatients. J Pers Assess. 1996;67(3):588-597. doi:10.1207/s15327752jpa6703_13

31. Hamilton M. A rating scale for depression. $J$ Neurol Neurosurg Psychiatry. 1960;23(1):56. doi:10.1136/jnnp.23.1.56

32. Rush AJ, Gullion CM, Basco MR, Jarrett RB, Trivedi MH. The inventory of depressive symptomatology (IDS): psychometric properties. Psychol Med. 1996;26(3):477-486. doi:10.1017/ S0033291700035558

33. Fried EI, von Stockert S, Haslbeck JMB, Lamers F, Schoevers RA, Penninx BWJH. Using network analysis to examine links between individual depressive symptoms, inflammatory markers, and covariates. Psychol Med. 2019;1-9. doi:10.1017/ S0033291719002770

34. Foley D, Ancoli-Israel S, Britz P, Walsh J. Sleep disturbances and chronic disease in older adults: results of the 2003 national sleep foundation sleep in America survey. J Psychosom Res. 2004;56 (5):497-502. doi:10.1016/j.jpsychores.2004.02.010

35. Buysse DJ. Insomnia, depression and aging. Assessing sleep and mood interactions in older adults. Geriatrics. 2004;59(2):47-51.

36. Goldberg JH, Breckenridge JN, Sheikh JI. Age differences in symptoms of depression and anxiety: examining behavioral medicine outpatients. J Behav Med. 2003;26(2):119-132. doi:10.1023/ A: 1023030605390

37. Gallo JJ, Anthony JC, Muthén BO. Age differences in the symptoms of depression: a latent trait analysis. J Gerontol. 1994;49(6):P251P264. doi:10.1093/geronj/49.6.P251

38. Fogel BS, Fretwell M. Reclassification of depression in the medically ill elderly. J Am Geriatr Soc. 1985;33(6):446-448. doi:10.1111/ j.1532-5415.1985.tb07157.x

39. Wahlin A, MacDonald SW, deFrias CM, Nilsson LG, Dixon RA. How do health and biological age influence chronological age and sex differences in cognitive aging: moderating, mediating, or both? Psychol Aging. 2006;21(2):318-332. doi:10.1037/08827974.21.2.318

40. Ohayon MM, Carskadon MA, Guilleminault C, Vitiello MV. Metaanalysis of quantitative sleep parameters from childhood to old age in healthy individuals: developing normative sleep values across the human lifespan. Sleep. 2004;27(7):1255-1273. doi:10.1093/sleep/ 27.7.1255

41. Cain SW, Dennison CF, Zeitzer JM, et al. Sex differences in phase angle of entrainment and melatonin amplitude in humans. $J$ Biol Rhythms. 2010;25(4):288-296. doi:10.1177/0748730410374943

42. Peterson MJ, Benca RM. Sleep in mood disorders. Sleep Med Clin. 2008;3(2):231-249.

43. Ford DE, Cooper-Patrick L. Sleep disturbances and mood disorders: an epidemiologic perspective. Depress Anxiety. 2001;14(1):3-6. doi:10.1002/da.1041

44. Chang LY, Chang HY, Lin LN, Wu CC, Yen LL. Disentangling the effects of depression on trajectories of sleep problems from adolescence through young adulthood. J Affect Disord. 2017;217:48-54. doi:10.1016/j.jad.2017.03.067

45. Zhang J, Lam SP, Li SX, et al. Insomnia, sleep quality, pain, and somatic symptoms: sex differences and shared genetic components. Pain. 2012;153(3):666-673. doi:10.1016/j.pain.2011.12.003

46. Verbrugge LM. Gender and health: an update on hypotheses and evidence. J Health Soc Behav. 1985;26(3):156-182. doi:10.2307/ 2136750 
47. Lieban RW. Gender and symptom sensitivity: report on a Philippine study. Am J Orthopsychiatry. 1985;55(3):446-450. doi:10.1111/ j.1939-0025.1985.tb03462.x

48. Department of Household Registration. Population aged 15 and over by age, sex and educational attainment; 2020. Available from: https:// www.ris.gov.tw/app/portal/346. Accessed June 20, 2020.

49. Kessler RC, Birnbaum H, Bromet E, Hwang I, Sampson N, Shahly V. Age differences in major depression: results from the national comorbidity survey replication (NCS-R). Psychol Med. 2010;40 (2):225-237. doi:10.1017/S0033291709990213

50. Mellinger GD, Balter MB, Uhlenhuth EH. Prevalence and correlates of the long-term regular use of anxiolytics. JAMA. 1984;251 (3):375-379. doi:10.1001/jama.1984.03340270053027

51. Tseng HY, Yu SH, Lee CY, et al. Sedative-hypnotic drug use among community-dwelling elderly in Taiwan. Int Psychogeriatr. 2018;30 (7):957-965. doi:10.1017/S1041610217002940
52. Perlis ML, Giles DE, Mendelson WB, Bootzin RR, Wyatt JK. Psychophysiological insomnia: the behavioural model and a neurocognitive perspective. J Sleep Res. 1997;6(3):179-188. doi:10.1046/j.1365-2869.1997.00045.x

53. Lundh LG, Broman JE. Insomnia as an interaction between sleep-interfering and sleep-interpreting processes. J Psychosom Res. 2000;49(5):299-310. doi:10.1016/S0022-3999(00)00150-1

54. Buysse DJ, Angst J, Gamma A, Ajdacic V, Eich D, Rossler W. Prevalence, course, and comorbidity of insomnia and depression in young adults. Sleep. 2008;31(4):473-480. doi:10.1093/sleep/31.4.473

55. Ryder AG, Yang J, Zhu X, et al. The cultural shaping of depression: somatic symptoms in China, psychological symptoms in North America? J Abnorm Psychol. 2008;117(2):300-313. doi:10.1037/ 0021-843X.117.2.300

\section{Publish your work in this journal}

Nature and Science of Sleep is an international, peer-reviewed, open access journal covering all aspects of sleep science and sleep medicine, including the neurophysiology and functions of sleep, the genetics of sleep, sleep and society, biological rhythms, dreaming, sleep disorders and therapy, and strategies to optimize healthy sleep.
The manuscript management system is completely online and includes a very quick and fair peer-review system, which is all easy to use. Visit http://www.dovepress.com/testimonials.php to read real quotes from published authors. 